\title{
Mapeamento das áreas de APPs de Nascentes cultivadas com eucalipto na bacia hidrográfica do Paraíba do Sul (trecho paulista)
}

\author{
Fernanda Viana Paiva Argüello ${ }^{1}$ \\ Getulio Teixeira Batista ${ }^{1}$ \\ Flávio Jorge Ponzoni ${ }^{2}$
}
${ }^{1}$ Programa de Pós-graduação em Ciências Ambientais da Universidade de Taubaté (UNITAU) Estrada Municipal Dr. José Luiz Cembranelli, 5.000- 12080-010 - Taubaté, SP, Brasil viana_fernanda@yahoo.com.br, getulio@agro.unitau.br
${ }^{2}$ Instituto Nacional de Pesquisas Espaciais - INPE, Av. dos Astronautas, 1758, 12.227-010 - São José dos Campos, SP, Brasil flavio@dsr.inpe.br

\begin{abstract}
The Paraíba do Sul basin is currently the focus of discussion of several environmental questions due to the past use of its natural resources. Recently, the region has been considered one of the most attractive for Eucalyptus spp. plantations and uncertainties have been raised concerning the conformance to the Brazilian Forest Code Law n 4771 and CONAMA Resolution $n^{\circ}$ 302/2002 related to the Permanent Preservation Areas (PPA). The purpose of this work was to map the PPA associated with springs (drainage starting points) of the Paraíba do Sul river basin and to estimate the amount of PPA that occurs in each municipality of São Paulo State and how much of this area has been reforested with Eucalyptus spp. using remote sensing and geoprocessing technologies. Results revealed that the municipalities near Serra do Mar and Mantiqueira mountains are among those with largest number of springs but lowest percentage of reforestation with Eucaliptus enhancing the importance of the preservation of these areas.
\end{abstract}

Palavras-chave: watershed, Eucalyptus spp. plantations, springs, environment, remote sensing, geoprocessing, bacia hidrográfica, plantações de Eucalyptus spp., nascentes, meio ambiente, sensoriamento remoto, geoprocessamento.

\section{Introdução}

A bacia hidrográfica do Paraíba do Sul, localizada no Estado de São Paulo é uma região histórica do Brasil, conhecida como o "Vale do Paraíba", atualmente, foco de discussão em função do plantio do eucalipto em parte das suas terras.

Os questionamentos sobre a utilização desse tipo de cultivo tornaram-se motivo de preocupação para a comunidade regional, pois, existem incertezas com relação à localização das áreas da bacia ocupadas por silvicultura e sua conformidade com o Código Florestal (Lei 4771/1965).

Outro questionamento freqüente é a associação da silvicultura de eucalipto com o rebaixamento do lençol freático. Segundo Ramos et al. (2007), a falta de água no solo ocorre pelo uso indevido do mesmo nas bacias hidrográficas, e não pela escassez de chuvas na região. Essa falta de água está associada à impermeabilização do solo impedindo a infiltração da água da chuva. De forma similar, Rodrigues et al. (2007) mencionam que é essencial a manutenção de condições adequadas para o sistema produtivo de uma bacia hidrográfica, a observação constante do estado de conservação de seus recursos naturais, o manejo adequado do solo, e o monitoramento da infiltração e da retenção das águas pluviais na bacia.

O Código Florestal Brasileiro (Lei n ${ }^{\circ} 4.771$, de 15 de setembro de 1965 e Resolução $\mathrm{n}^{\mathrm{0}} 302$, do Conselho Nacional do Meio Ambiente-CONAMA de 13 de maio de 2002) foi instituído para a proteção da flora, fauna e dos recursos hídricos e identifica áreas ambientalmente sensíveis que devem ser preservadas. Essas leis podem permitir a 
sustentabilidade de uma bacia hidrográfica, pois, sugerem total proteção para os recursos naturais pertencentes a essas áreas.

Segundo Maia e Valeriano (2001), com base no Código Florestal, as APPs incluem margens de rios, lagos, lagoas ou reservatórios, nascentes, topos dos morros, montes, montanhas e serras, encostas com declividade maior que $45^{\circ}$ e áreas situadas em altitudes maiores do que 1800 metros. Além das APPs, as áreas denominadas de Uso Restrito (AUR) correspondem às encostas entre $25^{\circ}-45^{\circ}$ e áreas de Reserva Legal (partes de propriedades rurais alocadas para a conservação do ambiente natural), são previstas no Código Florestal Brasileiro para evitar e retificar prejuízos ambientais causados pelo desmatamento.

O desenvolvimento dessa política ambiental trouxe ao país, a oportunidade de preservar e de conservar áreas importantes para a sustentabilidade de um sistema produtivo, indispensável à manutenção dos recursos naturais de uma bacia hidrográfica. Ribeiro et al. (2005) cita que a demarcação geográfica das reservas legais pendentes às normas ambientais constituídas, colaborou para integrar espaços aleatórios e causar progresso no formato e desempenho das áreas de preservação permanente.

Desta forma, a comunidade científica tem desenvolvido pesquisa para ampliar e elucidar o conhecimento sobre a questão que envolve tanto o Código Florestal Brasileiro (APPs) como o cultivo do Eucalyptus spp. (eucalipto) na região, pois, como citado por Almeida et al. (2007), a sustentabilidade dessa prática silvicultural em função do uso da água instiga discussão em todo o mundo e requer esforços para a compreensão dos possíveis efeitos desse tipo de atividade. Isso é ampliado pela lacuna na discussão dos possíveis sistemas de manejo que podem impactar a conservação da água, do solo nas áreas cultivadas e colocar em risco o abastecimento de água na região.

Entretanto, o desenvolvimento de pesquisa numa área tão extensa como o Vale do Paraíba, requer o uso de técnicas não convencionais. Atualmente, a utilização das geotecnologias tem contribuído efetivamente para o desenvolvimento dos trabalhos que visam à análise da distribuição espacial dos objetos, de forma que a integração de diversas informações temáticas tornou-se um importante instrumento para o auxílio no cumprimento das leis, pois, permite a análise de áreas protegidas legalmente pelo Código Florestal Brasileiro, como descrito por Ribeiro et al. (2005) e Catelani e Batista (2007), o beneficiamento da inspeção ecológica foi possibilitado pela verificação do Código Florestal brasileiro por meio da cartografia das APPs.

O objetivo deste trabalho foi demarcar as áreas de APPs referentes às nascentes e quantificar os municípios com áreas de APPs de nascente que foram plantadas com Eucalipto na bacia hidrográfica do Paraíba do Sul.

\section{Metodologia}

A área de estudo é a bacia hidrográfica do Paraíba do Sul (trecho paulista), situada no cone leste do Estado de São Paulo (Figura 1), na zona cartográfica 23, meridiano central $45^{\circ}$, com latitude do canto superior em $22^{\circ} 18^{\prime}$, 47' 'Sul e longitude $44^{\circ} 33^{\prime}$ 37' Oeste e, latitude do canto inferior em $23^{\circ} 27^{\prime} 31^{\prime \prime}$ 'Sul e longitude $46^{\circ} 00^{\prime} 31^{\prime \prime}$ Oeste. Segundo CEIVAP (2009) a bacia é composta por remanescentes da Mata Atlântica, situados nas áreas mais elevadas e de relevo mais acidentado, cuja cobertura vegetal no passado estendia-se por toda a área litorânea do Rio Grande do Norte ao Rio Grande do Sul e que, atualmente, restam apenas $11 \%$ da floresta original.

A Figura 1 mostra a cobertura vegetal da bacia em verde-claro, as áreas urbanas em lilás e corpos da água em preto, além das áreas brancas que representam à formação de nuvens. 


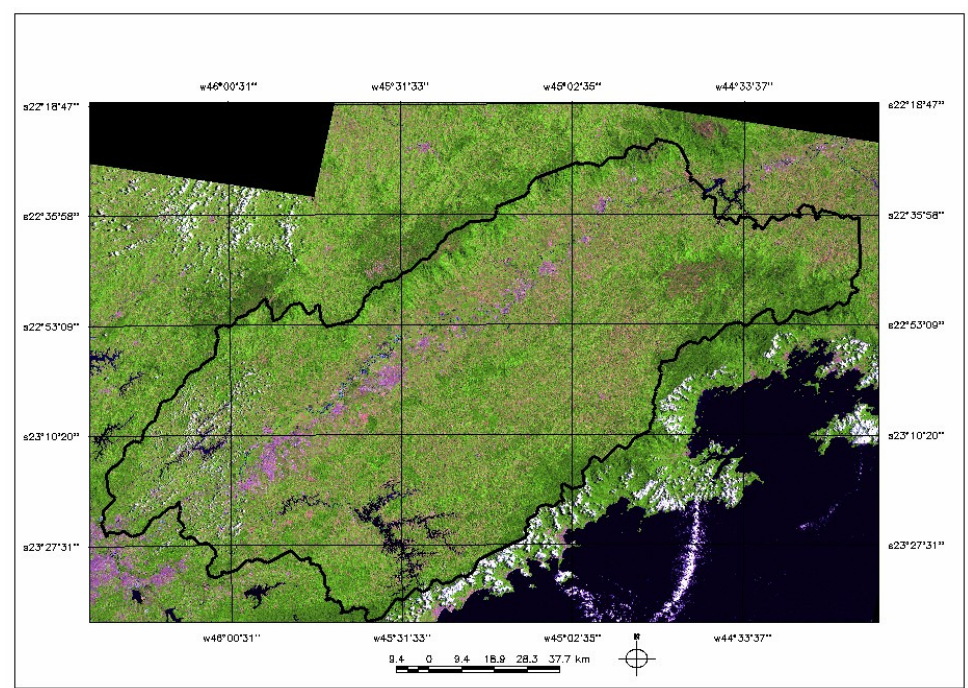

Figura 1. Composição colorida (bandas $3 \mathrm{R} 4 \mathrm{G}$ 5B) de uma imagem Landsat TM-5 (adquirida em 27 de fevereiro de 2003), mostrando a Bacia Hidrográfica Paraíba do Sul.

\subsection{Principais etapas da Metodologia}

Para a realização desse trabalho foram desenvolvidas três fases:

- $1^{a}$ Fase: Levantamento das áreas de APPs de nascente na bacia hidrográfica do Paraíba do Sul;

- $2^{\text {a }}$ Fase: Cruzamento das áreas de APPs de nascentes com o mapa de municípios que compõem a bacia;

- $3^{\text {a }}$ Fase: Cruzamento das áreas de reflorestamento em APPs de nascentes com os municípios;

O aplicativo utilizado nesse trabalho foi o SPRING - Sistema de Processamento de Informações Georreferenciadas versão Windows 4.3.2 (CAMARA et al., 1996), além de uma base de dados do Instituto Florestal de São Paulo contendo a distribuição das áreas ocupadas por reflorestamentos de essências exóticas e remanescentes da mata nativa no ano 2001, atualizada para 2007, seguindo metodologia descrita por Argüello (2009). Também foram utilizados alguns dados do banco de dados do "Projeto Recarga-Médio Vale do Rio Paraíba do Sul-SP”, realizado pela UNITAU em 2003 (Dias et al., 2009) e Cartas 1:50.000 do IBGE.

\subsubsection{Levantamento das áreas de APPs de nascente na bacia hidrográfica do Paraíba do Sul}

Nessa etapa do trabalho, foram delimitadas as áreas referentes às Áreas de Preservação Permanente (APP), estabelecidas pelo Código Florestal Brasileiro, no artigo $2^{\circ}$ da Lei $\mathrm{n}^{\circ} 4771$ de 15 Setembro de 1965 e especificadas pela Resolução $n^{\circ} 302$ do Conselho Nacional do Meio Ambiente (CONAMA), na data de 20 de março de 2002.

Essa fase se iniciou com a implementação de um banco de dados constituído pela compilação dos dados da rede de drenagem, obtidos diretamente do banco de dados do "Projeto Recarga Médio Vale Paraíba do Sul-SP" e limite da bacia hidrográfica do Paraíba do Sul do IBGE, escala 1:250.000.

As áreas correspondentes a $50 \mathrm{~m}$ no entorno de uma nascente são consideradas como Áreas de Preservação Permanente (APP), pelo Código Florestal Brasileiro. Por isso, foram demarcados os pontos centrais das nascentes em cada ponta que inicia uma linha de drenagem 
com a ferramenta "Edição Vetorial" e utilizando a função "Mapa de Distâncias", foram delimitadas todas as nascentes que ocorrem na bacia, conforme exemplificado na Figura 2.

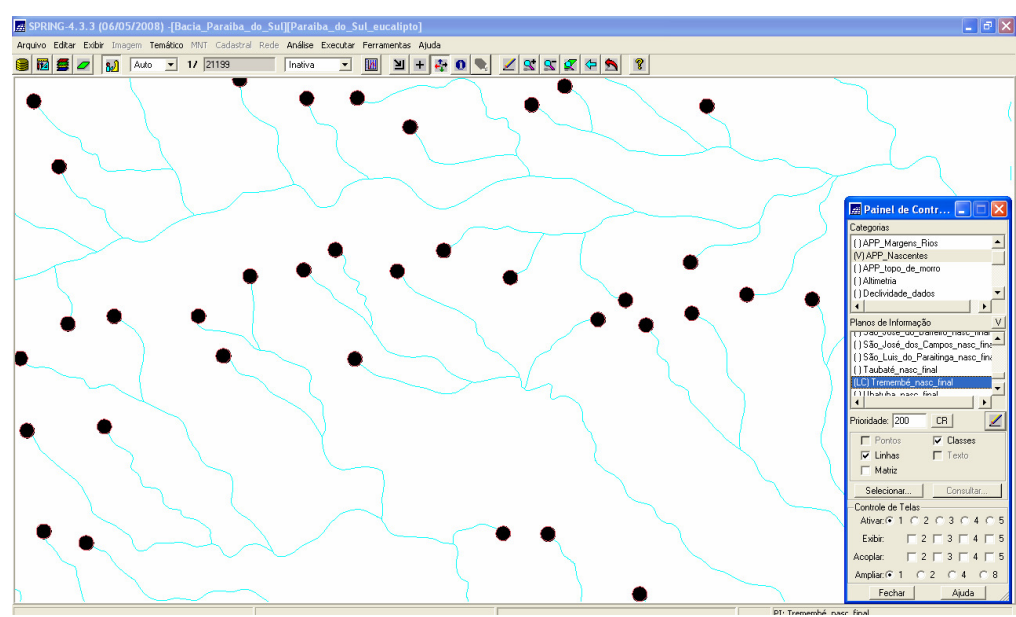

Figura 2. Exemplo de um trecho do mapa resultante do delineamento das APPs de nascentes (em preto).

\section{Mosaico das áreas de APPs de nascentes}

Nessa etapa, as áreas de APPs de nascentes foram transformadas usando a função "VetorMatriz" em matrizes com a resolução de $10 \mathrm{~m}$ x $10 \mathrm{~m}$ e unificadas em um só plano de informação com auxílio da função "Mosaico" do SPRING (Figura 3).

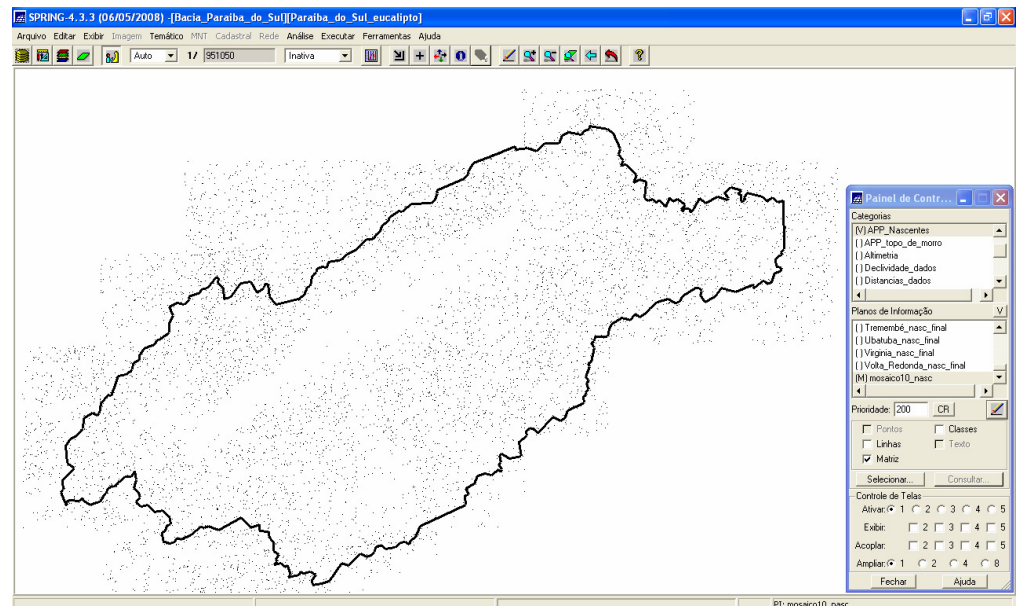

Figura 3. Mapa das APPs de nascentes da bacia hidrográfica Paraíba do Sul.

\subsubsection{Cruzamento das áreas de APPs de nascentes com o mapa de municípios que compõem a bacia}

Os dados das APPs de nascente foram cruzados com o mapa de municípios utilizando a função "Tabulação Cruzada" do SPRING, resultando na quantificação das áreas de APPs de nascentes em cada município do trecho paulista da bacia Paraíba do Sul.

\subsubsection{Cruzamento das áreas de reflorestamento em APPs de nascentes com os municípios}

Para essa fase, utilizando um programa escrito em "Legal" (Linguagem de modelagem do SPRING para análise algébrica) foi feito o recorte das áreas de APP nascente e eucalipto em cada município com base nos mosaicos de APPs de nascente e de reflorestamento em 2007. 
Diante desses resultados, foram gerados as matrizes com a ocorrência dos cultivos de eucalipto sobre as áreas de APPs de nascentes e novamente, utilizando a função "Tabulação Cruzada" para o cruzamento com o mapa de municípios, foram quantificados os dados de plantio dessa espécie nas APPs em cada um dos municípios que compõem a bacia no período referente a 2007.

Essa etapa se baseou no mapa temático de reflorestamento de 2007, previamente obtido por Arguello et al. (2009), que contém todas as áreas atualizadas com o reflorestamento de eucalipto e informações pertencentes aos municípios.

\section{Resultados e Discussão}

O processamento dos dados no cruzamento das áreas de APPs de nascentes com o mapa temático de municípios resultou na delimitação das áreas correspondentes a um raio de 50 metros a partir das nascentes em cada município, além das áreas de reflorestamento que foram cultivadas nessas áreas (Tabela 1).

A partir da análise dos resultados, pode-se observar que existe uma área considerável de nascentes em diversos municípios. Observa-se que Cunha apresenta a maior área em APPs de nascentes da bacia hidrográfica Paraíba do Sul, com 3190,4 hectares (Figura 4).

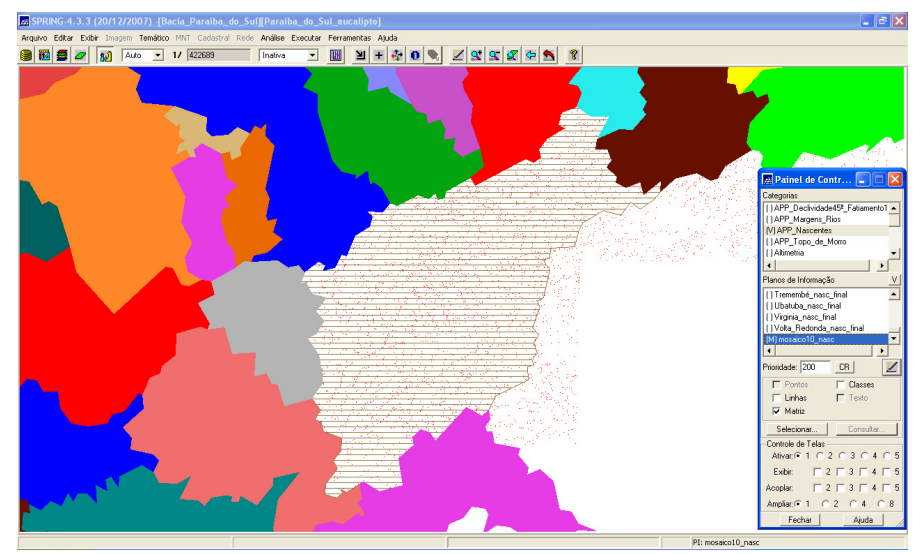

Figura 4. Exemplo da maior área de APPs de nascentes no município de Cunha com 3190,4 hectares (bege com hachuras) na bacia do Paraíba do Sul.

A Figura 5 mostra o município de Potim com a menor área em APPs de nascentes na bacia com 21,7 hectares.

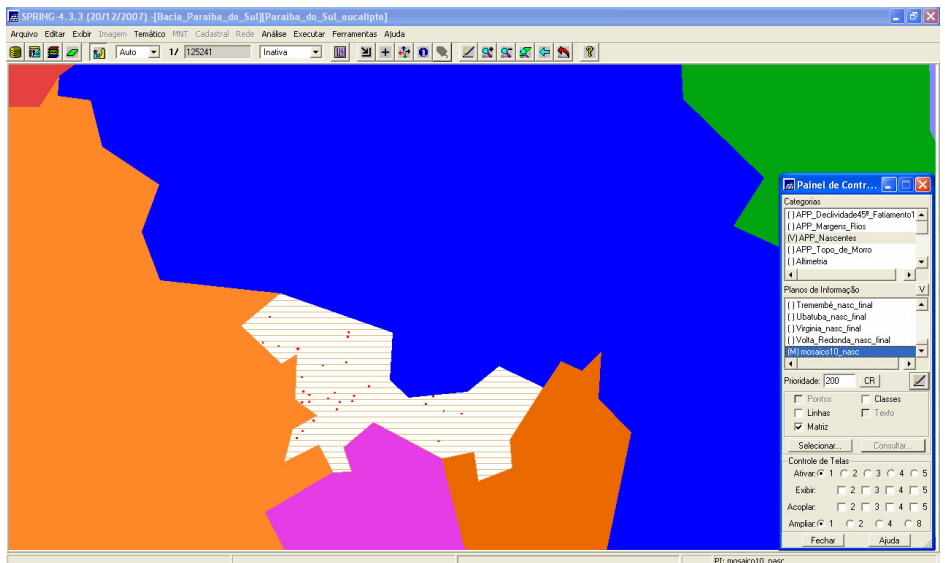

Figura 5. Exemplo da menor área de APPs de nascentes no município de Potim com 21,79 hectares (cor de rosa com hachuras) dentro dos limites da bacia do Paraíba do Sul. 
O município de Paraibuna com 474,4 hectares possui a maior área de cultivo de eucalipto em APPs de nascentes na bacia hidrográfica Paraíba do Sul (Figura 6).

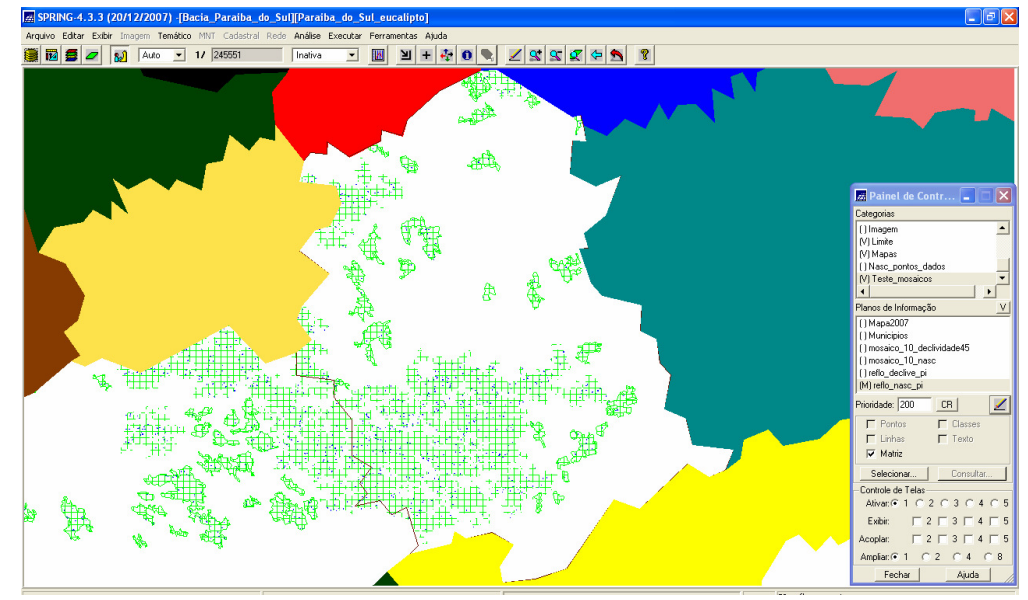

Figura 6. Exemplo da maior área de reflorestamento em APPs de nascentes no município de Paraibuna com 474,4 hectares (município em branco, reflorestamento em verde hachurado e nascente em pontos azuis) na bacia do Paraíba do Sul.

Tabela 1. Áreas de APPs de nascentes por município e áreas de reflorestamento com eucalipto nas APPs de nascentes nos diversos municípios que compõem a bacia hidrográfica do Paraíba do Sul (trecho paulista).

\begin{tabular}{|c|c|c|c|c|c|}
\hline Municípios & $\begin{array}{c}\text { APPs de } \\
\text { Nascentes por } \\
\text { município } \\
\text { (hectares) }\end{array}$ & $\begin{array}{c}\text { Reflorestamento } \\
\text { em Nascentes } \\
\text { (hectares) }\end{array}$ & Municípios & $\begin{array}{c}\text { APPs de } \\
\text { Nascentes } \\
\text { por } \\
\text { município } \\
\text { (hectares) }\end{array}$ & $\begin{array}{c}\text { Reflorestamento } \\
\text { em Nascentes } \\
\text { (hectares) }\end{array}$ \\
\hline Cunha & 3190,41 & 81,60 & Piquete & 505,12 & 29,95 \\
\hline São José dos Campos & 2241,03 & 161,28 & Queluz & 371,80 & 28,47 \\
\hline Paraibuna & 1511,62 & 474,45 & Igaratá & 363,63 & 42,87 \\
\hline Guaratinguetá & 1321,74 & 68,13 & Jambeiro & 337,64 & 63,42 \\
\hline São Luis do & 1263,42 & 131,95 & S. A. do Pinhal & 315,10 & 0,00 \\
\hline Paraitinga & & & & & \\
\hline São José do Barreiro & 1190,94 & 1,48 & Ubatuba & 313,73 & 0,00 \\
\hline Natividade da Serra & 1135,71 & 43,26 & São Sebastião & 277,50 & 0,00 \\
\hline Monteiro Lobato & 994,02 & 47,16 & S. B. do Sapucaí & 259,56 & 5,26 \\
\hline Bananal & 951,25 & 0,00 & Arapeí & 246,33 & 5,67 \\
\hline Taubaté & 950,25 & 136,09 & Lavrinhas & 229,54 & 20,08 \\
\hline Silveiras & 851,89 & 28,12 & Aparecida & 172,70 & 10,91 \\
\hline Jacareí & 792,63 & 62,39 & Tremembé & 168,98 & 28,29 \\
\hline Lorena & 760,29 & 78,53 & Roseira & 123,35 & 6,42 \\
\hline Areias & 744,0 & 30,90 & Santa Isabel & 115,27 & 0,00 \\
\hline Pindamonhangaba & 686,80 & 42,81 & Canas & 45,91 & 8,98 \\
\hline Guararema & 646,00 & 62,75 & Potim & 21,79 & 0,00 \\
\hline Lagoinha & 612,35 & 16,66 & Ilhabela & 20,08 & 0,00 \\
\hline Caçapava & 585,63 & 44,01 & & & \\
\hline Cachoeira Paulista & 578,94 & 7,10 & & & \\
\hline Cruzeiro & 546,54 & 7,52 & & & \\
\hline Caraguatatuba & 538,52 & 0,00 & & & \\
\hline Redenção da Serra & 531,52 & 85,42 & & & \\
\hline Santa Branca & 509,88 & 183,39 & & & \\
\hline Campos de Jordão & 509,52 & 16,18 & & & \\
\hline
\end{tabular}




\section{Conclusões}

Os resultados gerados a partir do cruzamento dos diversos mapas temáticos possibilitaram a demarcação das áreas de APPS de nascentes na bacia hidrográfica do Paraíba do Sul. Considerando a extensão dessa área, tornou-se evidente a eficácia da utilização das geotecnologias para esse tipo de análise, enfatizando o uso do aplicativo SPRING como facilitador para essa função.

Pôde ser observado que as áreas de reflorestamento em APPs de nascentes nos diversos municípios que compõem a bacia hidrográfica Paraíba do Sul apresentam uma área significativa de reflorestamento nessa classe de APP o que gera uma preocupação, pois, essas são áreas importantes para preservação e, por lei, devem ser preservadas.

Desta forma, os resultados desse trabalho possibilitaram o cumprimento do objetivo em questão que foi "demarcar as áreas de APPs referentes às nascentes e, permitiu quantificar os municípios com áreas de APPs de nascente que foram plantadas com eucalipto na bacia hidrográfica do Paraíba do Sul (trecho paulista)" e, dessa forma, propiciaram a identificação de áreas cuja localização geográfica próxima às serras, servem como berçário para a qualidade ambiental da bacia hidrográfica do Paraíba do Sul.

\section{Referências Bibliográficas}

ALMEIDA, J. C. R.; LACLAU, J. P.; GONÇALVES, J. L. M.; MOREIRA, R. M.; ROJAS, J. S. D. Índice de área foliar de Eucalyptus grandis em resposta à adubação com potássio e sódio. In: Anais I Seminário de Recursos Hídricos da Bacia Hidrográfica do Paraíba do Sul: o Eucalipto e o Ciclo Hidrológico, Taubaté, Brasil, 07-09 novembro 2007, IPABHi, p. 1-7.Disponível em: <http://www.agro.unitau.br:8080/dspace/bitstream/2315/ 82/1/1-7.pdf> . Acesso em:17 nov. 2008.

ARGUEllo, F. V. P.; BATISTA, G. T.; PONZONI, F. J. Análise da distribuição espacial das áreas de eucalipto no Cone Leste Paulista. In: XIV Simpósio Brasileiro de Sensoriamento Remoto, 2009, Natal. Anais do XIV Simpósio Brasileiro de Sensoriamento Remoto, 2009, v. 1, p. 5611-5616.

BRASIL. Decreto-lei n 4.771, de 15 de setembro de 1965. Institui o Novo Código Florestal Brasileiro e dá outras providencias. DOU de 16 de setembro de 1965. Brasília DF. 1965. Disponível em: <http://www.mma.gov.br/port/conama/res/res02/res30202.html>. Acesso 03 set 2008.

BRASIL. Conselho Nacional do Meio Ambiente. Resolução no 302, de 20 de março de 2002. Dispõe sobre parâmetros, definições e limites de Áreas de Preservação Permanente. DOU de 13 de maio de 2002. Brasília DF, 2002. Disponível em: <http://www.mma.gov.br/port/conama/res/res02/res30202.html>. Acesso 03 set 2009.

CÂMARA, G.; SOUZA, R. C. M.; FREITAS, U. M.; GARRIDO, J. SPRING: Integrating remote sensing and GIS by objected-oriented data modeling. J. Computers \& Graphics, 20(3), 395-403, 1996. Disponível em: <http://www.dpi.inpe.br/geopro/trabalhos/spring.pdf>. Acesso em: 17 nov. 2008.

CEIVAP. Comitê de Integração da Bacia Hidrográfica do Rio Paraíba do Sul. Dados geoambientais. Disponível em: <http://ceivap.org.br/bacia_1_2.php>. Acesso em: 05 de out 2009.

CATELANI, C. S.; BATISTA, G. T. Mapeamento das Áreas de Preservação Permanente (APP) do município de Santo Antonio do Pinhal, SP: um subsídio à preservação ambiental. Ambi-Agua, Taubaté, v. 2, n. 1, p. 3043, 2007. Disponível em: <http://www.agro.unitau.br/seer/index.php/ambi-agua/article/viewFile/1/68> . Acesso em: 22 set. 2008.

DIAS, N. W.; DINIZ, H. N.; TARGA, M. S.; BATISTA, G. T. Geospatial technology applied to the identification of groundwater recharge areas in northeastern São Paulo, Brazil. Ambi-Agua, Taubaté, v. 4, n. 2, p. 21-30, 2009. (doi:10.4136/ambi-agua.83).

IBGE-Fundação Instituto Brasileiro de Geografia e Estatística, Superintendência de Cartografia, Carta do Brasil-Escala 1:50.000. Proj. Universal Transversa de Mercator. Disponível em: $<$ http://biblioteca.ibge.gov.br/>. Acesso em: 29 nov. de 2008. 
RODRIGUES, C. JR.; TARGA, M. S.; BATISTA, G. T.; DIAS, N. W. Florestamento compensatório com vistas à retenção de água no solo da bacia hidrográfica do Ribeirão Itaim, Taubaté, SP. Anais I Seminário de Recursos Hídricos da Bacia Hidrográfica do Paraíba do Sul: o Eucalipto e o Ciclo Hidrológico, Taubaté, Brasil, 07-09 novembro 2007, IPABHi, p. 67-73.

MAIA, J. S.; VALERIANO, D. M. Transgressão do Código Florestal no Município de Piquete - SP. In: Simpósio Brasileiro de Sensoriamento Remoto, 10. (SBSR), 2001, Foz do Iguaçu. Anais... São José dos Campos: INPE, 2001. p. 611-616. CD-ROM, On-line. ISBN 85-17-00016-1. (INPE-8272-PRE/4062). Disponível em: <http://urlib.net/dpi.inpe.br/lise/2001/09.19.09.16>. Acesso em: 27 set. 2009.

Oliveira, I. S.; BATISTA, G. T.; CASTELANI, C. S.; Minicurso: Área de Preservação Permanente (APP). In: Encontro Água \& Floresta, 7-9 nov. 2006, Taubaté. Repositório Eletrônico Ciências Agrárias. Taubaté: UNITAU, 2006. 78p. (Coleção Ciências Florestais). Disponível em: $<$ http://hdl.handle.net/2315/66>. Acesso em 26 jun. 2008.

RAMOS, J. G. A.; DIAS, H. C. T. Escoamento superficial de água de chuva no cultivo do eucalipto. Anais I Seminário de Recursos Hídricos da Bacia Hidrográfica do Paraíba do Sul: o Eucalipto e o Ciclo Hidrológico, Taubaté, Brasil, 07-09 novembro 2007, IPABHi, p. 363-365.

RIBEIRO, C. A. A. S. et al. O desafio da delimitação de áreas de preservação permanente. Rev. Árvore, Viçosa, v. 29, n. 2, abr. 2005. Disponível em <http://www.scielo.br/scielo.php?script=sci_arttext\&pid= S0100-67622005000200004\&lng=pt\&nrm=iso $>$. Acesso em 27 set. 2009. doi: 10.1590/S010067622005000200004 . 